\title{
Historical aspects of cardiovascular services in Nepal
}

\section{Dr. Ram Kishor Shah*, MD (Cardiology)}

Himalayan Kingdom Nepal, birth place of Devi Sita, Lord Ram and Buddha is situated between two giant countries. The heart of Nepal is the beautiful flora and mighty Himalayas. Ayurveda was the main modality of therapy for most ancient Nepalese people. After the treaty of Sugauli in 1816 AD, a Residency office of British India was established in Kathmandu. Allopathic medical service was provided by the doctors posted in the residency. It was from that period the people in Kathmandu came to know about a system of medicine other than Ayurveda. After many years of this type of arrangement, Bir Hospital actually came into existence in 1889 AD, more than one hundred years ago.

The department of medicine of Bir Hospital was first established in the year 1961 AD. Before that all the beds were under the direct care and supervision of the medical superintendent. When the department of medicine became fully functional, the need for developing various sub-specialities of medicine in the direction was made in late 1970s. Cardiology unit was established in 2042 BS (1985 AD.) As a part of department of medicine. In-door started in Teaching Hospital (TUTH) on 24 Falgun 2042 BS with cardiac services under the guidance of Prof G.P. Acharya.

\section{Electrocardiography}

In 1940 AD. When a highly placed dignitary of Nepalese Royal family became sick, a Physician with ECG machine came from Calcutta. ECG machine went out of order, then one aeroplane was sent to Calcutta to bring another ECG machine to have an electrocardiogram done.

In the field of cardiology, the electrocardiography (ECG) services was first introduced in Nepal by Dr. Edgar Miller at Shanta Bhawan Hospital in Patan in 1956 AD. Dr M. R. Pandey was the first Nepalese doctor to introduce ECG services in Bir Hospital in 1962 AD. Dr Brig Gen Thakur Nath Bhattarai introduced ECG service in Sri Chandra Military Hospital in 1962. Now ECG service is available in most of the Hospitals and Nursing homes of Kathmandu valley and outside the valley. 


\section{Cardiac Monitor, Defibrillator, Phono And Apex Cardiography.}

'The first cardiac monitor and defibrillator in the country were introduced in 1968 AD Followed by phono and apex Cardiography in 1972 AD in Bir Hospital.

\section{Coronary Care Unit}

The First coronary care unit (CCU/ICU) in Nepal was started in Bir Hospital on 7th Falgun 2031 BS (1974 AD) on the auspicious occasion of the coronation of his majesty the King. It was inaugurated by Her majesty the Queen herself. In the Teaching Hospital CCU/ICU started on 24th Falgun 2042 BS

(1985), having all cardiac facilities. Medicare National Hospital was the $1^{\text {st }}$ hospital to start ICC/CCU in private sector in 1997. In our country, at present, Birendra Military Hospital, Patan Hospital, Kanti Children Hospital, Sahid Ganga Lal National Heart Centre, Medicare National Hospital. Norvic Heart Centre have CCU/ICU services. These facilities are .also available in some places within and outside Kathmandu valley,

\section{Non- Invasive Cardiac Lab}

Stress Electrocardiography, the first Bicycle stress ECG service using treadmill was installed in Bir Hospital in 1984 AD (2041-9-1). In 1988 AD (2045-10-10), a modern computerised Treadmill machine (TMT) was installed. Now TMT service is being provided at TUTH, Medicare, Norvic, Sahid Ganga Lal National Heart Centre and Sidhartha Hospital.

\section{Echocardiography and Doppler Machine}

The Echo Cardiograph with facilities for Doppler Studies was installed on the day that His Majesty the King inaugurated the new OPD building of Bir Hospital. The Echo with colour Doppler was first started in TUTH (1993 AD). This service is also available in Kanti Children' Hospital, Sahid Ganga Lal Heart Centre, Medicare National Hospital, Norvic Heart Centre, Siddhartha Hospital, Lalitpur Heart Clinic, Om Nursing Home, and in other places within and outside Kathmandu valley. Dobutamine stress Echo started in TUTH in 1996 AD by Dr. Arun Sayami. 


\section{Holter Monitoring And Ambulatory B.P Monitoring}

The first holter monitoring in the country was established in Bir Hospital in the year 1985 AD. The first Holter analyzing system was introduced by Medicare National Hospital in private sector in 1997. Before this doctors used to send the cassette to India for analysis. Ganga Lal Heart Centre is also roviding this service. Ambulatory B.P. Monitoring is available in Ganga Lal Heart Centre and Lalitpur Heart Clinic.

\section{Nuclear cardiology}

First MUGA Scan was carried out by Dr. Basu from India in 1980 AD in Bir hospital.

\section{Invasive Cardiac Lab}

\section{Pacemaker Service}

Temporary Pacing: Temporary transvenous pacemaker (TP 1) service first started in Bir Hospital.Dr. M.P. Shrestha with the help of Indian cardiologists was the first to introduce a temporary pacemaker in 1975 AD. Later Dr M.R Bajracharya continued the same since 1979 AD.

Permanent Pacing: For the first time in Nepal a permanent pacemaker (PP1) was implanted on Mr.Ganga Ram Shrestha on 2043.6.21 for sick sinus syndrome. Teletronics Australia launched PPI programme with audio visual lectures and workshop on 7th Oct, 1986 (Ashwin 2046). Subsequent inplants done by Dr. M.R. Bajracharya (few early cases being helped by Dr L.B. Thapa). TUTH started TPI and PPI in 1989 AD. Now TPI and PPI services are available only in TUTH and Norvic Heart Centre.

\section{Cardiac Catheterization}

First coronary angiogram was done under the guidance of Dr. David Coles with the help of Angioscope in Bir Hospital. Rest of the cases of congenital and valvular heart diseases were carried out by Nepalese doctors. First pulmonary angiogram was done in TUTH in 1990 AD. Now cardiac Cath Lab has already been installed in Sahid Ganga Lal National Heart Centre and Ist coronary angiography has been performed on 14 July, 2000 with assistance of Dr. R. Lochan from India. 


\section{Heart Surgery in Nepal}

Cardiothoracic surgery is being done at Bir Hospital since the sixties. Dr. D.N. Gongal performed first thoracotomy in 1963 A.D. and the first mitral valvotomy in 1964 A.D. in Santa Bhawan Hospital mitral valvotomy was done by Dr Robert Ballery in 1966 A.D.

In 1988, with the help of ADRA NEPAL, a comprehensive cardiac team from Sydney, Australia visited Bir Hospital and performed some heart surgery. Dr L.B. Thapa made a fresh begining in heart surgery in late eighties. He made close heart surgery a regular affair in Bir Hospital.

In 1989, Dr. Alan W. Gale of Australia performed the first open heart surgery with an excellent result. Both the Australian and the Bir Hospital teams were actively involved. Nepalese Cardiac surgeons Dr. L. B. Thapa and Dr D.P. Pokharel performed open heart surgery in 1992 A.D with Foreign cardiac team in Bir Hospital.

In 1993, ADRA Nepal and Indian team organized closed heart surgery training and performed CMC in TUTH. Later Cardiac team from Loma Linda USA performed 30 open heart surgery cases, Prof. Dr. Govinda Sharma and Dr. Bhagwan Koirala started cardiac surgery in TUTH in 1995 AD. VSD Closure was done by Dr. Bhagwan Koirala and Dr. B.M. Singh in TUTH in 1997 AD with full Nepalese cardiac team. In Nepal, first CABG operation has been done by Dr. D.P. Pokharel in Bir Hospital on 4th Ashad. 2057.

Hopefully invasive cardiology and Heart Surgery will make a break through in Nepal in near future. Saheed Ganga Lal National Heart Centre is coming into senario very soon. Days are not far off when Nepal will be self sufficient in cardiac care.

\section{Acknowledgement}

I would like to thank Dr. M. R. Pandey, Dr. L. B. Thapa, Prof Dr. G. P. Acharya, Prof Dr. Arun Sayami, Dr. D. P. Pokharel. Dr. M. R. Bajracharya, Dr. D. B. Karki, Dr. A. B. Upadhyay, Dr. L. P. Tibrewala, Dr. T. N. Bhattarai, Dr. B. M. Singh, Dr. P. R. Regmi for their valuable informations about the history of Cardiac care in Nepal.

* Cardiologist, Cardiac Unit, Bir Hospital, G.P.O Box 80II. Kathmandu. NEPAL. Tel.528871 email-rkshah40@hotmail.com 